\title{
ANDRÉ GORZ - UNE VIE [Willy Gianinazzi, 2016, Paris, Editions La Decouverte]
}

\author{
Nuno Miguel Cardoso Machado \\ Socius, ISEG, Universidade de Lisboa, Lisboa, Portugal
}

André Gorz (1923-2007) é sobejamente conhecido como um dos principais intervenientes no debate contemporâneo acerca da crise da "sociedade do trabalho". No entanto, poucas pessoas dão a devida atenção à longa trajetória intelectual de Gorz, marcada por várias ruturas. Pode, com efeito, falar-se de vários “Gorz": nos anos 50 foi um dos principais pensadores existencialistas, nos anos 60 foi um dos grandes impulsionadores da Nova Esquerda, nos anos 70 foi o fundador da Ecologia Política e, finalmente, a partir dos anos 80 , foi um crítico acérrimo da sociedade capitalista assente no trabalho, na mercadoria e no valor económico.

Para além disso, estamos perante um indivíduo sui generis, cindido numa identidade tripartida: a vida pessoal de Gérard Horst, o jornalista Michel Bosquet e o filósofo André Gorz. Naturalmente que a biografia intelectual é a tradição disciplinar mais adequada para abordar oito décadas de uma vida tão rica e diversificada. Todavia, não têm sido muitos os investigadores a aceitarem o desafio (quanto a mim) aliciante de escrutinar Gorz.

Foram publicadas quatro biografias intelectuais de Gorz nos últimos 20 anos. Em três dessas obras, as principais virtudes são simultaneamente as maiores fraquezas: a concisão implica uma perda de profundidade da análise (cf. Lodziak e Tatman, 1997); a ênfase excessiva no contexto intelectual significa que, por vezes, a evolução da teoria de Gorz é difícil de acompanhar e reter (cf. Little, 2013 [1996]); a análise minuciosa dos seus três primeiros livros - de cunho existencialista - implica um tratamento mais superficial da sua obra tardia (cf. Bowring, 2000). A obra de Josué Pereira da Silva era, até agora, provavelmente o retrato mais rigoroso, equilibrado e fiel de André Gorz (cf. Silva, 2002).

Esta investigação primorosa encontrou finalmente um rival à sua altura em André Gorz - Une Vie. Willy Gianinazzi teve acesso a vários arquivos - mormente ao espólio de André Gorz presente no IMEC (Institut Mémoires de l'Edition Contemporaine), situado em Caen - que albergam material inédito, onde se destacam numerosos manuscritos e a correspondência de Gorz. Ademais, é de frisar o trabalho de pesquisa notável de Gianinazzi, porquanto foi capaz de "desenterrar" dezenas de textos gorzianos em publicações de circulação bastante limitada. Gianinazzi realizou, ainda, diversas entrevistas, recolhendo testemunhos de vários amigos íntimos e pensadores que privaram com Gorz ao longo dos anos. O estudo deste manancial de informação permitiu a Gianinazzi lançar uma nova luz sobre diversos aspetos biobibliográficos da obra gorziana e, simultaneamente, realizar uma excelente contextualização social, económica e intelectual.

Gianinazzi adota naturalmente uma abordagem cronológica. O livro está dividido em cinco partes. Assim, na primeira parte, o autor procede a uma análise da vida de Gorz durante as décadas de 1940 e 1950, mas, antes, estuda minuciosamente a infância e a juventude de Gorz. Gianinazzi destaca o ambiente familiar difícil, 
marcado pelos conflitos entre a sua mãe (católica) e o seu pai (judeu), assim como as angústias do jovem Gorz numa Áustria assediada pelo antissemitismo. Gorz não consegue construir uma identidade estável nem encontrar um sentido para a sua vida, sentindo-se completamente perdido no mundo que o rodeia. Não surpreende, por isso, que sua primeira influência intelectual tenha sido a filosofia existencialista de Sartre (p. 25).

O início da sua relação com Doreen Keir, em 1947, bem como o exercício da profissão de jornalista foram fulcrais para que Gorz conseguisse vencer o seu isolamento (pp. 21, 27 e 42). Gorz aceitou a escrita como um modo de vida, como a "única maneira de existir" (p. 29, itálico nosso). Em 1951, já a viver em França, Gorz começa a trabalhar no periódico Paris-Presse (p. 54). Em 1955 prossegue a sua carreira no L'Express, ficando encarregue da atualidade económica internacional ( $\mathrm{p}$. 56), tema que o acompanhará nas três décadas seguintes (p. 57).

Entre 1945 e 1955 Gorz redige um manuscrito intitulado Fundamentos para Uma Moral, que apenas será publicado em 1975 (p. 31). Em 1958 publica uma obra de cariz autobiográfico chamada $O$ Traidor, que obtém um enorme sucesso. Nestes dois primeiros livros, a preocupação de Gorz prende-se com o sujeito, nomeadamente com o problema da autonomia. Gorz critica a alienação individual em nome da autenticidade sartreana (p. 62).

A descoberta da obra de Marx revela que "a incompletude do ser" se insere num "contexto mais vasto, de ordem social e económica" (p. 67). Em AMoral da História, livro publicado em 1959, a alienação deixa, pois, de ser estudada do ponto de vista individual e passa a ser apreendida como um fenómeno social. Neste livro, Gorz adota também a teoria messiânica do proletariado (p. 75). Segundo Gianinazzi, Gorz combina o marxismo e o existencialismo de maneira "fecunda" (p. 73).

A segunda parte da obra de Gianinazzi acompanha André Gorz durante a década de 1960. Neste período, o compromisso de Gorz com a teoria marxista vai aprofundar-se. Gorz dedica-se ao estudo da crítica da economia política marxiana, nomeadamente de O Capital e dos Grundrisse (p. 90). Gorz é "impermeável" à ascensão do estruturalismo althusseriano, que transforma o sujeito em suporte passivo das estruturas sociais (p. 90). Ao invés, Gorz é influenciado pelo operaismo italiano, que defende a luta autónoma do proletariado contra a "organização capitalista do trabalho" (p. 94).

Isto é evidente em Estratégia Operária e Neocapitalismo, livro de 1964. O controlo operário da produção e a autogestão são a pedra de toque do marxismo gorziano (pp. 95-96 e 102). No seguimento das teses de Serge Mallet, Gorz identifica a chamada "nova classe operária", composta pelos trabalhadores mais qualificados, como o sujeito revolucionário por excelência (p. 104) e como o modelo exemplar da "práxis criativa" (p. 105) capaz de apreender a economia no seu conjunto e, portanto, de autogeri-la. Em síntese, o socialismo proposto por Gorz consubstancia-se na conquista do poder político pelo proletariado e na socialização dos meios de produção (p. 106).

A terceira parte incide sobre a década de 1970. Depois de um longo périplo pelos EUA, onde se encontra com várias figuras da contracultura estado-unidense, Gorz regressa persuadido de que "as formas e os objetivos clássicos da luta de 
classes não podem transformar a sociedade" (p. 159). A inflexão do pensamento de Gorz pode ser entendida no quadro mais amplo da emergência dos "novos movimentos sociais" (p. 164). Estes têm um cariz heterogéneo, englobando os movimentos ecologista, feminista, antimilitarista, etc., que ocuparam o lugar deixado vago pelo descrédito dos partidos políticos (p. 210).

Gorz postula, agora, uma crítica ecológica da técnica e da ciência capitalistas (p. 159), assim como dos seus efeitos destrutivos para os seres humanos e para a natureza. Gorz defende uma "recusa civilizacional, aquela do produtivismo" (p. 162, itálico no original). Entre os autores que influenciaram a mudança do pensamento de Gorz contam-se Hannah Arendt, Simone Weil, Jacques Ellul, Günther Anders e, sobretudo, Ivan Illich (pp. 168-169).

Em Ecologia e Política, publicado em 1975, André Gorz propõe uma síntese de Marx e de Illich sob a forma de uma "tecno-crítica" (p. 174): a racionalidade instrumental da tecnologia e da economia capitalista ameaça a sobrevivência do próprio planeta. A lógica do lucro conduz à "pilhagem dos recursos" e à "poluição do meio ambiente" (p. 205). Para contrariar este estado de coisas, Gorz defende, na sequência de Illich, a criação de ferramentas conviviais, ecologicamente sustentáveis e capazes de estimularem a autonomia dos indivíduos.

Na quarta parte, Gianinazzi analisa o período mais conhecido da vida de André Gorz: as décadas de 1980 e 1990. Em 1980, André Gorz publica o seu livro polémico intitulado Adeus ao Proletariado (p. 215). Nesta obra, “o mito prometaico do proletariado revolucionário é abandonado" (p. 215). O proletariado interiorizou as categorias capitalistas e, na esmagadora maioria dos casos, envolveu-se em meros conflitos distributivos no seio dessas mesmas categorias. A lógica da produção capitalista nunca foi colocada em causa.

Gorz deposita, então, as suas esperanças no conjunto dos seres humanos "supranumerários": os desempregados, os precários e todos aqueles que, de um modo geral, rejeitam a condição operária (p. 219). Gorz designa este grupo por "não-classe dos não-trabalhadores". Os seus membros possuem em comum "as aspirações a uma vida melhor que sabem ser irrealizável através do emprego e do rendimento que este acarreta" (p. 219).

Gorz rejeita a visão teleológica da história de Marx, mas não a sua crítica da economia política, que permanece insubstituível para analisar a evolução do modo de produção capitalista (p. 216). Na sequência da chamada 3. ${ }^{a}$ Revolução Industrial - aquela da microeletrónica - assistiu-se à disseminação da automação. $\mathrm{O}$ trabalho humano é progressivamente excluído do processo de produção imediato, como atestam os níveis de desemprego crescentes (p. 217). Na perspetiva de Gorz, a crise do trabalho é, simultaneamente, a crise do capital, ou seja, a incapacidade estrutural de reprodução das relações sociais mercantis.

Para além disso, o trabalho é a substância do capital e, portanto, uma categoria eminentemente negativa; não se trata de apropriar coletivamente os meios de produção, mas de transformar radicalmente a produção, fazendo-a perder o seu cariz mercantil. A sua "visão do comunismo" passa, pois, pela "abolição do trabalho" (p. 220, itálico no original). Isto é possível porque o trabalho não é uma categoria antropológica (p. 262). Em Metamorfoses do Trabalho, publicado em 1988, Gorz 
fala de uma "invenção do trabalho", assinalando o seu caráter especificamente hodierno (p. 262). A constituição histórica do trabalho - abstrato, homogéneo, mercantil, assalariado - é indissociável da emergência de uma esfera económica desincrustada da sociedade.

O esquema utópico de uma "sociedade dual", proposto por Gorz, consiste na contração contínua da esfera heterónoma - o locus do trabalho assalariado e da racionalidade económica - e na expansão concomitante da esfera da autonomia, i.e., das atividades livremente escolhidas pelos indivíduos de acordo com os seus gostos, desejos, fantasias, etc., que são um fim em si mesmas (p. 253).

Finalmente, na quinta parte, Gianinazzi aborda os últimos anos de vida de Gorz, até à sua morte em 2007, colmatando essa lacuna na literatura secundária. Se na década de 1990 o pensamento de Gorz denota um pendor "reformista e pragmatista" (p. 268), na década de 2000 opera-se uma radicalização na sua teoria, algo extremamente invulgar numa pessoa com uma idade tão avançada. Esta radicalização deve-se à descoberta da denominada "crítica do valor" (wertkritik) e, em particular, das obras de Moishe Postone e Robert Kurz (pp. 329-331).

Em Ecologica, livro publicado a título póstumo, Gorz adota a teoria da crise kurziana, defendendo que o capital esbarra com o seu limite interno absoluto (p. 335): "Visto que 'a quantidade média de trabalho abstrato cristalizada nas mercadorias é, em última análise, aquilo que determina [...] o valor', então, de modo inelutável, 'com a contração do volume de trabalho [...] o valor de troca dos produtos tende a baixar, assim como o volume dos lucros' "' (p. 329).

Tal como Marx havia previsto nos Grundrisse, a riqueza dissocia-se do dispêndio de trabalho e depende, ao invés, do estado geral de desenvolvimento técnico, tecnológico e científico (p. 304). Na era da automação, o conhecimento devém a principal força produtiva (p. 312). O processo de produção deixa progressivamente de ser um processo de trabalho (p. 313), colocando em xeque a criação de valor económico (p. 314). Face à impossibilidade crescente de se valorizar na economia real, o capital lança-se furiosamente na esfera financeira, onde simula a sua acumulação através da formação de bolhas gigantescas sucessivas de capital fictício (pp. 329 e 337).

Se é verdade que esta crise terminal - que será um longo processo de decomposição (pp. 330-331) - encerra o perigo de decadência na barbárie, ela também abre a possibilidade emancipatória de um outro tipo de sociedade, pautada por relações não mercantis (pp. 331 e 344). Numa carta de 2007, Gorz falará, no seguimento de Kurz, da necessidade imperiosa de uma "rutura categorial" (p. 335). Na ótica do último Gorz, é possível desatrelar completamente a produção de riqueza (material e imaterial) da forma-valor e da forma-mercadoria (p. 334).

Em André Gorz - Une Vie, Willy Gianinazzi consegue transmitir ao leitor, de maneira exemplar, que Gorz procurou sempre estabelecer uma harmonia entre as suas críticas teóricas e a sua vida pessoal (p. 6). No seu entendimento, o intelectual, servindo-se das armas do pensamento crítico, deve revelar as possibilidades que se abrem a "um outro mundo que seja humanamente desejável" (p. 7).

Neste sentido, a imagem que devemos reter de André Gorz é a de alguém que foi, durante toda a sua vida, um rebelde em dois sentidos: "enquanto indivíduo 
inassimilado" que rejeitou qualquer espécie de "conformismo social" e enquanto "escritor subversivo" (p. 5). Gorz recusou a atitude confortável de adormecer à sombra dos seus escritos pretéritos e da notoriedade granjeada. Ao invés, o autor continuou, até ao fim da sua vida, a rever as suas ideias e a "explorar novos territórios intelectuais" (p. 8).

São poucas as falhas que podem ser apontadas ao trabalho magistral de Gianinazzi. Destaco sobretudo a (relativa) pouca atenção dada à bibliografia secundária - assaz numerosa - e, em especial, às críticas que foram sendo lançadas a aspetos específicos da teoria de Gorz ao longo da sua vida. Creio que o autor poderia ter feito um esforço suplementar para enquadrar pelo menos parte dessa literatura. Saliento, ainda, a ausência de uma conclusão, porquanto um balanço geral teria permitido terminar o livro de forma menos abrupta. Isto não invalida o facto de estarmos perante a melhor biografia intelectual de André Gorz alguma vez escrita, pautada pelo rigor e erudição de um historiador conhecedor do seu ofício.

\section{Referências bibliográficas}

Bowring, Finn (2000), André Gorz and the Sartrean Legacy - Arguments for a Person-Centred Social Theory, Londres, Macmillan; e Nova Iorque, St. Martin's Press.

Little, Adrian (2013 [1996]), The Political Thought of André Gorz, Nova Iorque, Routledge (2. 'a edição).

Lodziak, Conrad, e Jeremy Tatman (1997), André Gorz - A Critical Introduction, Londres e Chicago, Pluto Press.

Silva, Josué Pereira da (2002), André Gorz - Trabalho e Política, São Paulo, Annablume.

Nuno Machado. Estudante do doutoramento em Sociologia Económica e das Organizações do Instituto Superior de Economia e Gestão da Universidade de Lisboa, e bolseiro de doutoramento no Socius - Centro de Investigação em Sociologia Económica e das Organizações. Licenciado em Economia (ISEG) e mestre em Sociologia Económica e das Organizações (ISEG).

E-mail: nuno.cocas.machado@gmail.com 
